PREPARED FOR THE U.S. DEPARTMENT OF ENERGY, UNDER CONTRACT DE-AC02-76CH03073

PPPL-3982

PPPL-3982

UC-70

NSTX Tangential Divertor Camera

by

A.L. Roquemore, Ted Biewer, D. Johnson,

S.J. Zweben, Nobuhiro Nishino, and V.A. Soukhanovskii

July 2004

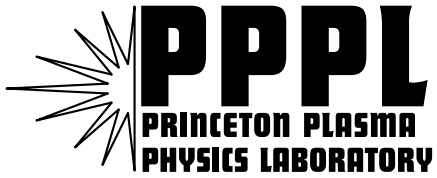

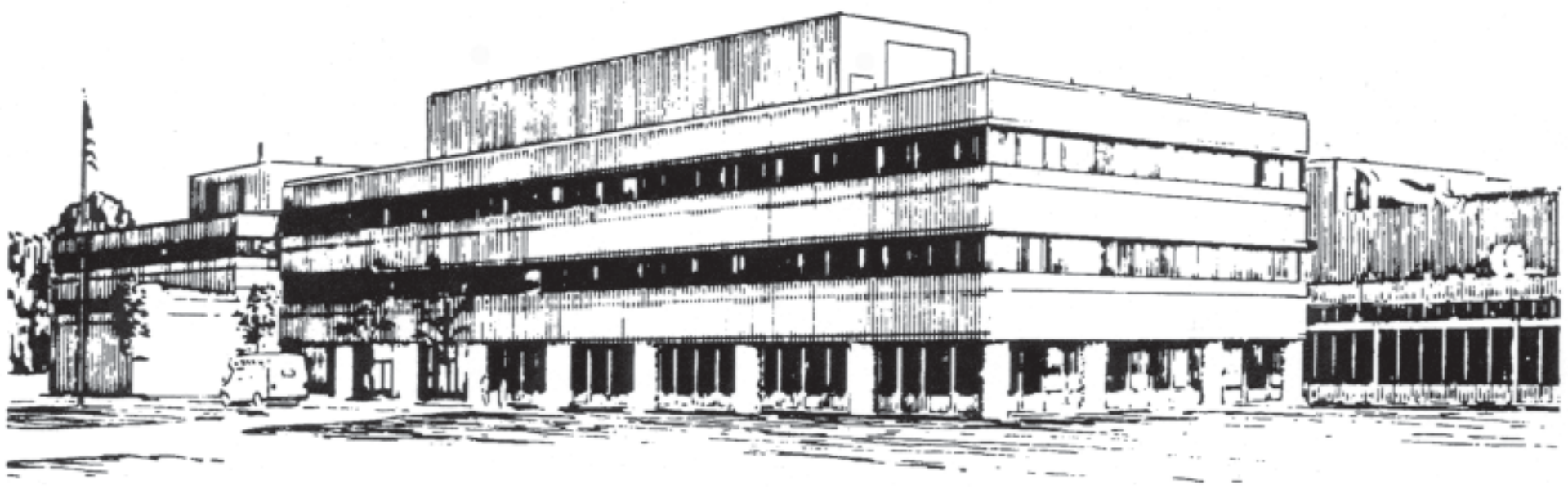

PRINCETON PLASMA PHYSICS LABORATORY PRINCETON UNIVERSITY, PRINCETON, NEW JERSEY 


\section{PPPL Reports Disclaimer}

This report was prepared as an account of work sponsored by an agency of the United States Government. Neither the United States Government nor any agency thereof, nor any of their employees, makes any warranty, express or implied, or assumes any legal liability or responsibility for the accuracy, completeness, or usefulness of any information, apparatus, product, or process disclosed, or represents that its use would not infringe privately owned rights. Reference herein to any specific commercial product, process, or service by trade name, trademark, manufacturer, or otherwise, does not necessarily constitute or imply its endorsement, recommendation, or favoring by the United States Government or any agency thereof. The views and opinions of authors expressed herein do not necessarily state or reflect those of the United States Government or any agency thereof.

\section{Availability}

This report is posted on the U.S. Department of Energy's Princeton Plasma Physics Laboratory Publications and Reports web site in Fiscal Year 2004. The home page for PPPL Reports and Publications is: http://www.pppl.gov/pub_report/

DOE and DOE Contractors can obtain copies of this report from:

U.S. Department of Energy

Office of Scientific and Technical Information

DOE Technical Information Services (DTIS)

P.O. Box 62

Oak Ridge, TN 37831

Telephone: (865) 576-8401

Fax: (865) 576-5728

Email: reports@adonis.osti.gov

This report is available to the general public from:

National Technical Information Service

U.S. Department of Commerce

5285 Port Royal Road

Springfield, VA 22161

Telephone: $1-800-553-6847$ or

(703) $605-6000$

Fax: (703) 321-8547

Internet: http://www.ntis.gov/ordering.htm 


\title{
NSTX Tangential Divertor Camera *
}

\author{
A. L. Roquemore, Ted Biewer, D. Johnson, S. J. Zweben, \\ Princeton plasma Physics Laboratory, Princeton New Jersey, 08543 \\ Nobuhiro Nishino,
}

Hiroshima University, Hiroshima Japan

V.A. Soukhanovskii,

Lawrence Livermore National Laboratory, Livermore, California,94550

\begin{abstract}
Strong magnetic field shear around the divertor $x$-point is numerically predicted to lead to strong spatial asymmetries in turbulence driven particle fluxes. To visualize the turbulence and associated impurity line emission near the lower x-point region, a new tangential observation port has been recently installed on NSTX. A reentrant sapphire window with a moveable in-vessel mirror images the divertor region from the center stack out to $\mathrm{R} \sim 80 \mathrm{~cm}$ and views the $\mathrm{x}$-point for most plasma configurations. A coherent fiber optic bundle transmits the image through a remotely selected filter to a fast camera, for example a 40500 frames/sec Photron CCD camera. A gas puffer located in the lower inboard divertor will localize the turbulence in the region near the x-point. Edge fluid and turbulent codes UEDGE and BOUT will be used to interpret impurity and deuterium emission fluctuation measurements in the divertor.
\end{abstract}




\section{Introduction:}

Tangential camera views of the lower divertor have been implemented on D-III D ${ }^{1}$, C-Mod ${ }^{2}$ and $\mathrm{JET}^{3}$. These systems have been used to characterize divertor phenomena such as particle and heat flux propagation, especially in regards to recycling and detached plasmas at the inner and outer divertor regions, impurity line emission, Edge Localized Modes (ELMS), impurity transport and more. Recent results from the 3-D edge turbulence code, BOUT, have predicted that the strong magnetic field shear in the region of the $x$-point will effectively isolate local turbulence in the divertor region from turbulence upstream. ${ }^{4}$ Recently, a tangential view of the lower divertor was developed on NSTX with the primary purpose of studying turbulence and associated transport in the lower divertor region.

As the result of a collaboration between Hiroshima University in Japan and PPPL, an Ultima SE high speed camera manufactured by Photron has been fielded on NSTX specifically to study divertor phenomena. This camera has previously been applied to divertor studies on NSTX but from a downward viewing midplane port. ${ }^{5} \mathrm{~A}$ test of the prediction by BOUT may be obtained by imaging the divertor region with a fast camera and by utilizing the lower dome gas injectors located in the inner divertor which were installed for the 
coaxial helicity injection experiments. This would supplement the existing gas puff imaging diagnostic already viewing the outer midplane. ${ }^{6}$

\section{Experimental Configuration}

A horizontal port at Bay F on the lower dome of NSTX is located at approximately the height of a standard x-point. The passive plates are located about $60 \mathrm{~cm}$ from the port flange. One of the passive plate tiles, $12.8 \mathrm{~cm}$ high by $6.4 \mathrm{~cm}$ wide, and its copper backing plate were cut away to initially give radial viewing access to the divertor region. Removal of a small section of passive plate had little effect on the wall stabilization properties of the passive plates as the plasma is never in close proximity to the passive plates at this location.

In order to increase the field of view, a re-entrant sapphire window on the end of a $50 \mathrm{~cm}$ long by $5 \mathrm{~cm}$ diameter tube was installed to reach near the cutout in the passive plate. To view the divertor region tangentially through a radially-viewing aperture required angling the reentrant tube slightly off-radial by $\sim 10^{\circ}$ and employing a stainless steel polished mirror on the end to aim the view tangentially through the cutout. The primary passive plates are angled inboard at their bottom to conform to the plasma shape. When viewing through this aperture tangentially, the effective aperture becomes an inverted and truncated right triangle. Fig. 1 shows the 
approximate area of the lower divertor that is being imaged. By adjusting the mirror angle and the location of the fiber, it is possible to see the center stack, the inner strike points and the $x$-point, but not the outer strike point in one view. The outer strike can be viewed by adjusting the mirror angle to look more outboard.

The mirror doubles as a shutter to protect the sapphire window during glow discharge cleaning, boronization and bakeout. An inspection of the window during a recent vent showed the back of the mirror to be heavily coated but the window and inner mirror surface were still in pristine condition. Stainless steel shim stock is wrapped around the last six inches of the tube and stood off from the tube by $4 \mathrm{~mm}$. This acts as a heat shield and is required because the end of the tube is approximately one centimeter away from one of the bakeout lines that reaches $\sim 375^{\circ} \mathrm{C}$.

The image is transferred away from the window by a 2.7 meter long 400X400 fiber optic bundle manufactured by Schott. A $50 \mathrm{~mm}$ output lens is close coupled to the camera lens and both lenses are set to infinity. Intermediate to the two lenses is a remotely operated rotating filter wheel that holds up to four interference filters (generally $\mathrm{H} \square, \mathrm{HII}, \mathrm{Cl}$, and $\mathrm{CIII}$ ) with one blank aperture. The camera lens is a $90 \mathrm{~mm}$ remotely controlled lens with variable iris, focus and zoom controls. When the camera is operated at its fastest frame rate using only the central $64 \times 64$ pixels, the lens can be zoomed out so that the image fills the full active array. 
The camera is a charge-coupled device (CCD) camera and is capable of operating from 30 to 4500 frames per second (fps) in the full frame(slow) mode using its full complement of pixels(256X256 pixels). At faster frame rates, the number of active pixels are progressively reduced until the maximum frame rate of $40500 \mathrm{fps}$ is achieved with a corresponding active array of $64 \times 64$ pixels. The active subset of pixels are centrally located within the array which simplifies the optics. Once triggered, the camera takes frames until its memory is full. This results in 8012 data frames in the full frame mode and 131072 data frames at $40500 \mathrm{fps}$. More than 3 seconds of data can be taken at the $40500 \mathrm{fps}$ so that a full discharge ( $\leq 1 \mathrm{sec}$ ) on NSTX can be recorded. The camera memory is more than five hundred megabytes which is an excessively large amount of data to store for every discharge so that each shot is recorded in local memory and only a subset of data, usually amounting to about 50 megabytes per discharge, is selected around the time of interest and permanently archived. The optical components are shown in Fig. 2.

The spatial resolution at the highest speed at the tangency plane of the x-point is estimated to be of order $1 \mathrm{~cm}$ in the horizontal plane and approximately $0.7 \mathrm{~cm}$ in the vertical direction.

\section{Operation}

Initial operation has concentrated on optimizing the optics to obtain the best view. A $6 \mathrm{~mm}$ input lens with a $40^{\circ}$ fov and $12 \mathrm{~mm}$ input 
lenses with a $20^{\circ}$ fov have been tried. The six $\mathrm{mm}$ lens gives the best coverage of the divertor but uses only about $50 \%$ of the pixels. The $12 \mathrm{~mm}$ lens gives better resolution at the expense of a reduced viewing area so that the optimum lens has not yet been obtained. A larger diameter fiber will also improve the light throughput which is especially useful when the interference filters are used.

The lower dome gas injectors are presently configured so that all injectors open at the same time. Work is underway to allow each injector to be operated individually. Also, in the present configuration, only deuterium gas can be used in the dome injectors because they share a gas bottle with the injectors on the center stack injector which are used almost every discharge. Preliminary gas puffs using all four of the lower dome injectors, each injecting one Torr-liter of deuterium gas, successfully injected into a plasma near the end of the pulse and a noticeable enhancement over the ambient plasma light was observed. The $40500 \mathrm{fps}$ rate was sufficient to reveal a non-coherent churning motion of the plasma, resembling boiling water, and can only be appreciated in movie form. Meaningful localized measurements will have to wait for operation with a single injector.

\section{Initial results}

Even without the gas puff, many interesting phenomena have been observed. The formation and evolution of the x-point (Fig. 3) is clearly observed along with its inner strike point with the proper orientation of the fiber optic lens. Also, $\mathrm{H}$-mode transitions and 
associated ELMS are easily distinguishable and what are believed to be MARFS are routinely formed on the center stack.

An example of the camera performance is given in Fig. 4. The evolution of a small ELM is recorded using an $\mathrm{H}_{\square}$ filter. The $\mathrm{x}$-point on this discharge was below the fov of the camera. A localized region of emission builds up near the center stack and rapidly collapses downward but stays contained within the envelope of the leg of the $x$ point. A small reduction in the stored energy is observed. Each frame in Fig. 4 is $25 \square \sec$ duration so that the formation and decay of the ELM is over in $\sim 250 \mu \mathrm{sec}$.

\section{Future Plans}

The main improvement to the camera system is to obtain a view of the entire divertor region. This may be obtained by enlarging the limiting aperture in the passive plates or by relocating the window just behind the plane of the plates. The second method would probably result in rapidly coating the window by plasma operation. The gas puff may localize the turbulence so that spatial inversion of the image is not required. However, other measurements requiring profile information will need to have an inversion performed. This is clearly the case, since the outer strike point is often visible on the far side of the divertor especially in the toroidally symmetric gap between the inner and outer divertor region. Also, a second view is being considered to image the divertor from the top of the machine. More than three fourths of the machine would be visible from an upper view 
if a re-entrant port is implemented. The view from above would shed light on many issues regarding toroidal symmetry, as well as yield information on the various divertor operating regimes.

\section{Acknowlegments}

The authors would like to thank Tom Holoman for help with the design, fabrication and installation of the optical system and to Jim Strachan and Rejesh Maingi for many useful discussions. This work supported by the DoE contract DE-ACO2-76CH03073 


\section{References}

${ }^{1}$ M.E. Fenstermacher et. al., Rev. Sci. Instrum 68, 974 (1997)

${ }^{2}$ C.J. Boswell et. al. Rev. Sci. Instrum. 72, 935 (2001)

${ }^{3}$ A. Huber et. al., $30^{\text {th }}$ EPS Conference on Contr. Fusion and Plasma

Phys. St. Petersburg, Russia, (2003)ECA Vol.27A,P-3.199

${ }^{4}$ M.V. Umansky, et. al., Plasma Edge Theory conference, San Diego

California Sept 3-5, 2003, UCRL-JC-155308

${ }^{5}$ Nishino N, et. al. J. Plasma Fusion Res. (Japan) Rapid

Communications RC 0030,(2002)

${ }^{6}$ S. J. Zweben et. al., Nucl. Fusion 44, 134 (2004) 


\section{Figure Captions}

FIG.1 Elevation of NSTX showing the approximate area imaged by the divertor fast camera. At the x-point the imaged area extends from the center stack out $\sim 50 \mathrm{~cm}$. The imaged area can be adjusted outboard by changing the mirror angle. FIG. 2 Optical and mechanical components of the divertor fast camera.

FIG. 3 Photos of the x-point during L-mode operation. FIG. 4 Evolution of a Type III ELM using H-alpha filter. Each frames is $25 \mu \mathrm{ec}$ duration. The emission rapidly increases near the center stack and collapses in $250 \mu$ sec. 


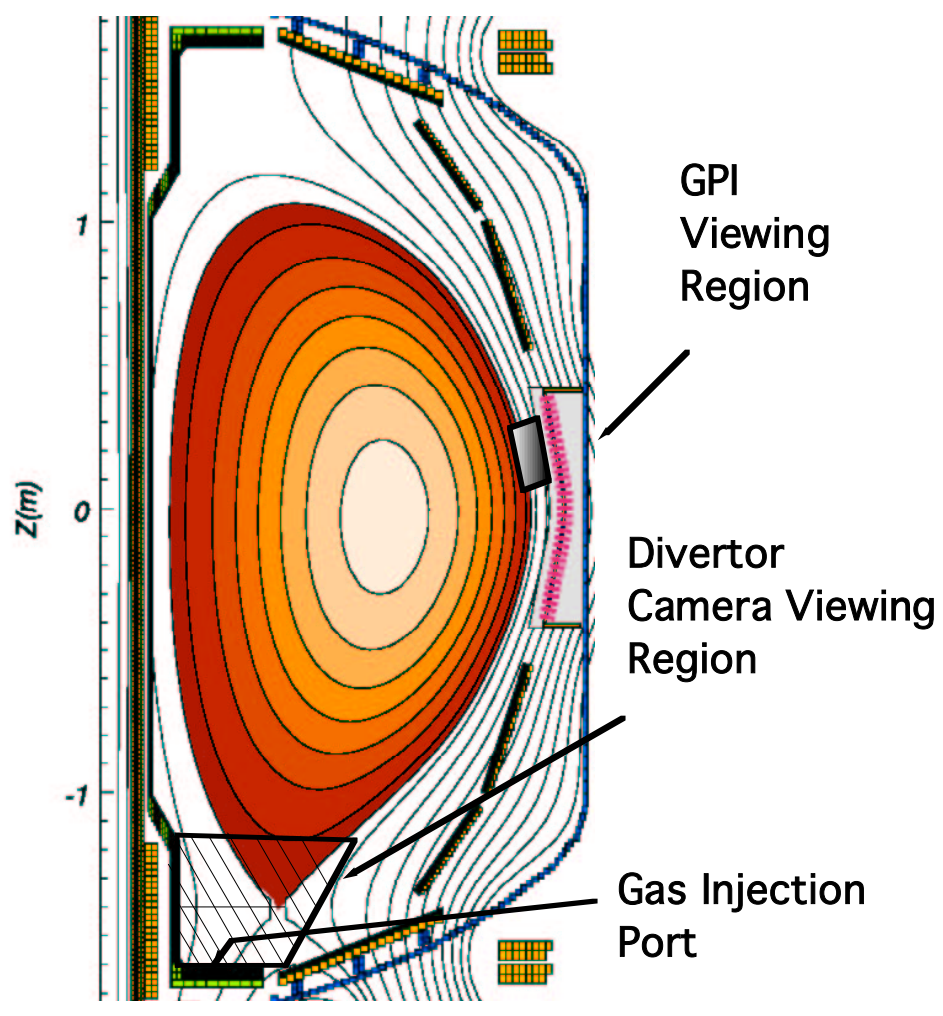

Fig 1. 


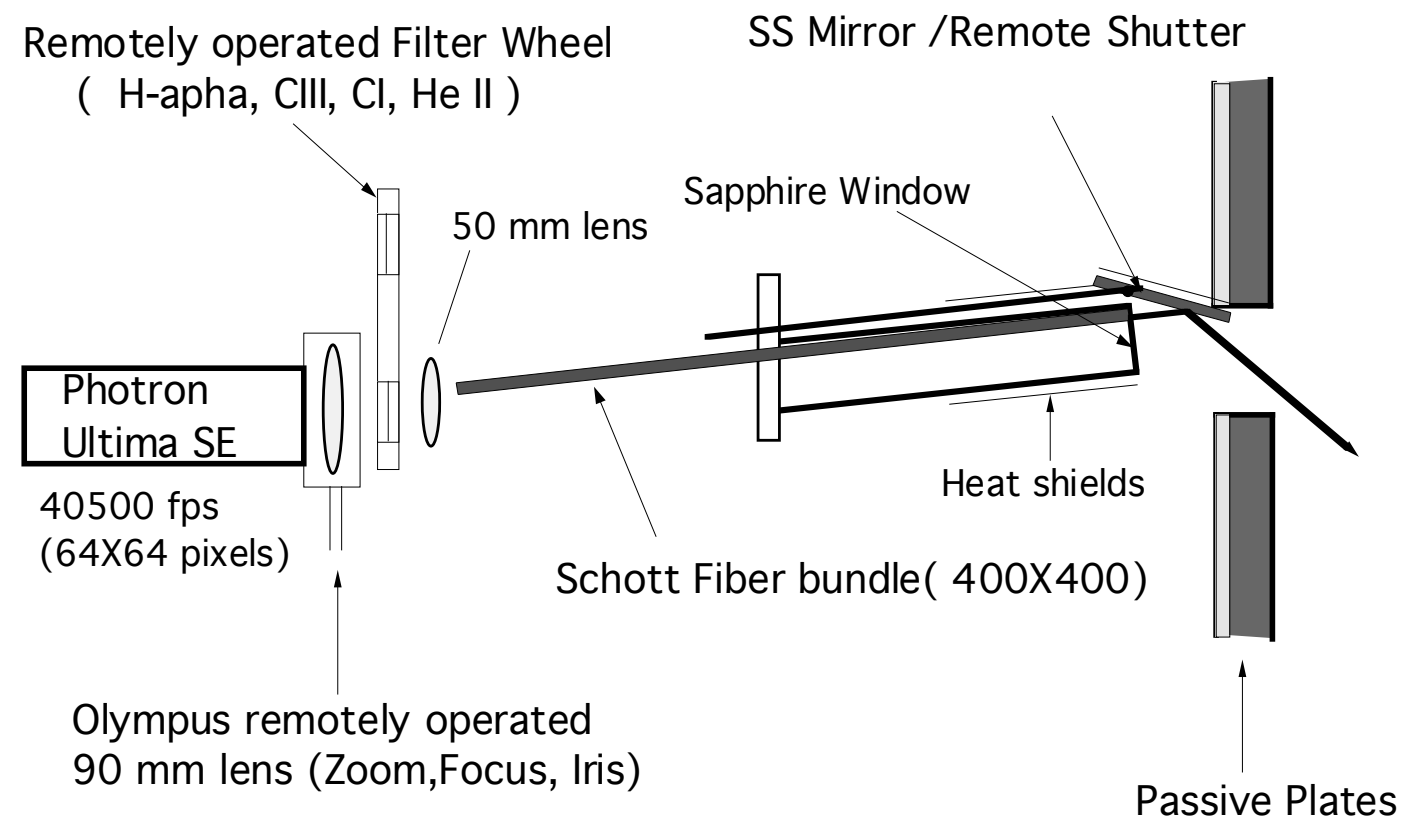

Fig. 2 


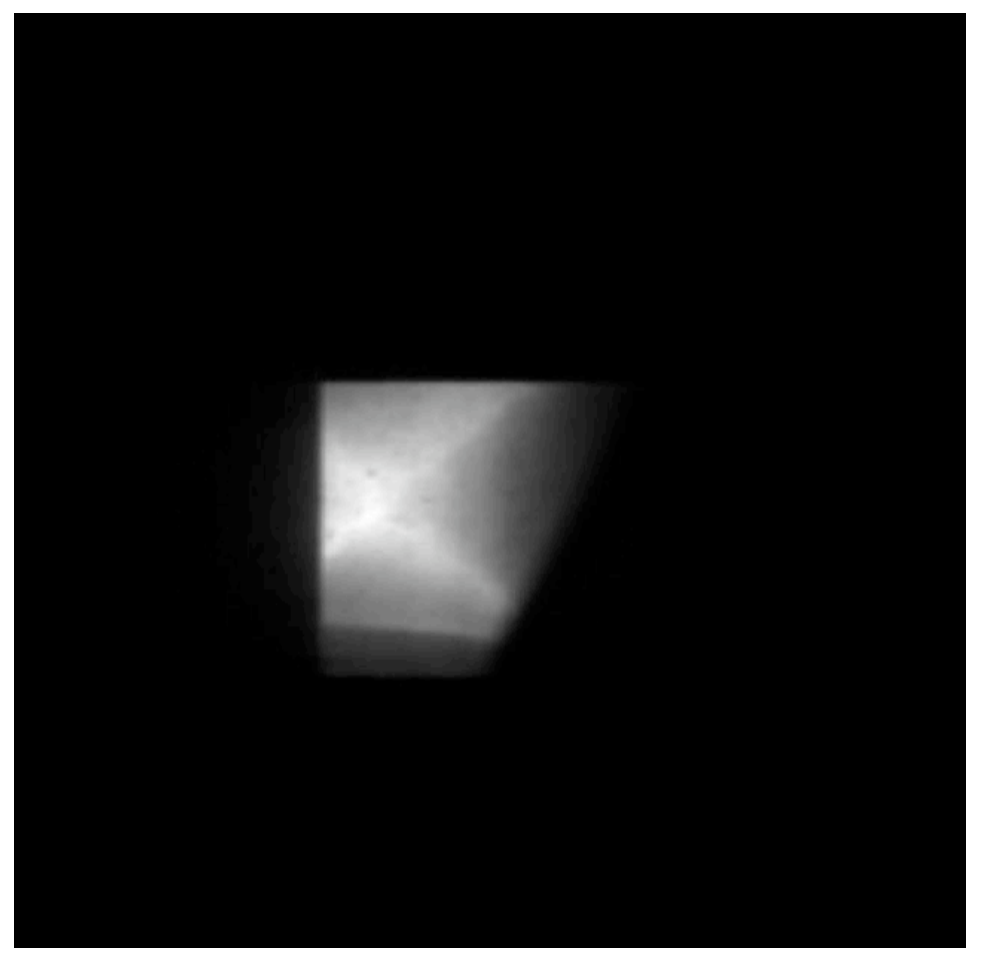

Fig 3 


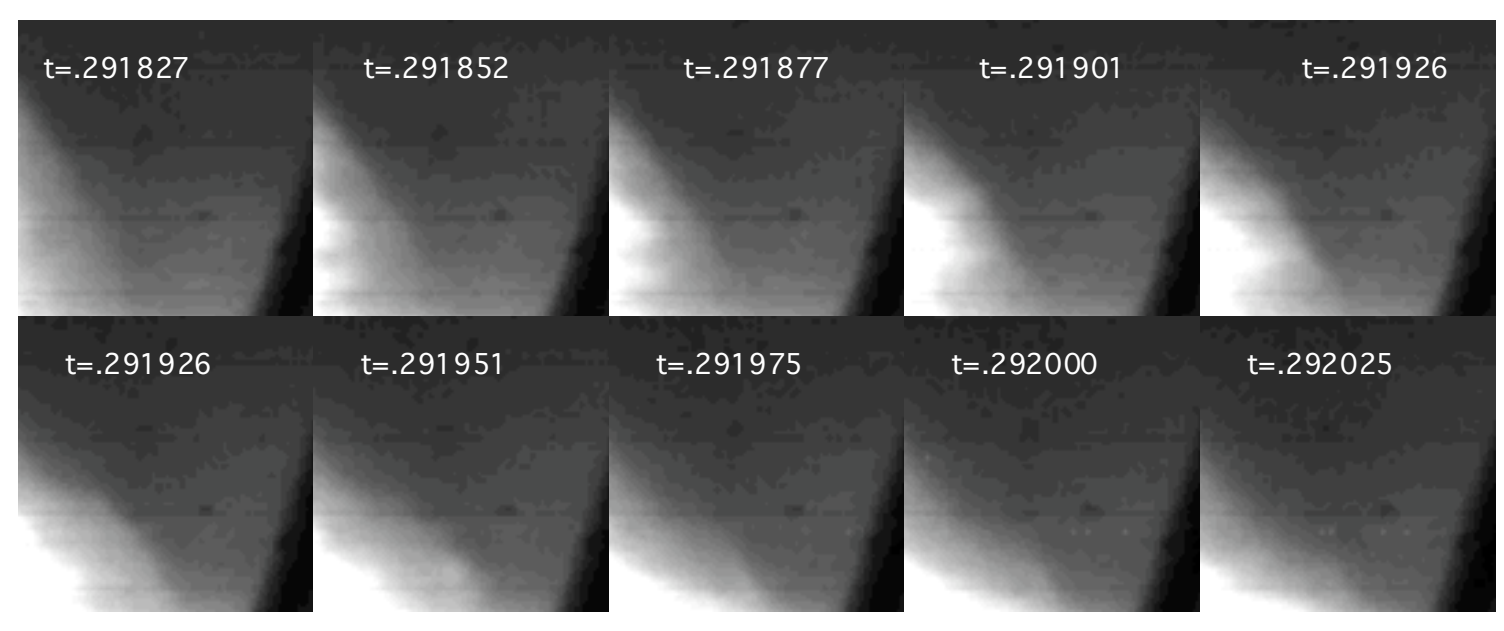

Fig. 4 


\section{External Distribution}

Plasma Research Laboratory, Australian National University, Australia

Professor I.R. Jones, Flinders University, Australia

Professor João Canalle, Instituto de Fisica DEQ/IF - UERJ, Brazil

Mr. Gerson O. Ludwig, Instituto Nacional de Pesquisas, Brazil

Dr. P.H. Sakanaka, Instituto Fisica, Brazil

The Librarian, Culham Laboratory, England

Mrs. S.A. Hutchinson, JET Library, England

Professor M.N. Bussac, Ecole Polytechnique, France

Librarian, Max-Planck-Institut für Plasmaphysik, Germany

Jolan Moldvai, Reports Library, Hungarian Academy of Sciences, Central Research Institute for Physics, Hungary

Dr. P. Kaw, Institute for Plasma Research, India

Ms. P.J. Pathak, Librarian, Institute for Plasma Research, India

Ms. Clelia De Palo, Associazione EURATOM-ENEA, Italy

Dr. G. Grosso, Instituto di Fisica del Plasma, Italy

Librarian, Naka Fusion Research Establishment, JAERI, Japan

Library, Laboratory for Complex Energy Processes, Institute for Advanced Study, Kyoto University, Japan

Research Information Center, National Institute for Fusion Science, Japan

Dr. O. Mitarai, Kyushu Tokai University, Japan

Dr. Jiangang Li, Institute of Plasma Physics, Chinese Academy of Sciences, People's Republic of China

Professor Yuping Huo, School of Physical Science and Technology, People's Republic of China

Library, Academia Sinica, Institute of Plasma Physics, People's Republic of China

Librarian, Institute of Physics, Chinese Academy of Sciences, People's Republic of China

Dr. S. Mirnov, TRINITI, Troitsk, Russian Federation, Russia

Dr. V.S. Strelkov, Kurchatov Institute, Russian Federation, Russia

Professor Peter Lukac, Katedra Fyziky Plazmy MFF UK, Mlynska dolina F-2, Komenskeho Univerzita, SK-842 15 Bratislava, Slovakia

Dr. G.S. Lee, Korea Basic Science Institute, South Korea

Institute for Plasma Research, University of Maryland, USA

Librarian, Fusion Energy Division, Oak Ridge National Laboratory, USA

Librarian, Institute of Fusion Studies, University of Texas, USA

Librarian, Magnetic Fusion Program, Lawrence Livermore National Laboratory, USA

Library, General Atomics, USA

Plasma Physics Group, Fusion Energy Research Program, University of California at San Diego, USA

Plasma Physics Library, Columbia University, USA

Alkesh Punjabi, Center for Fusion Research and Training, Hampton University, USA

Dr. W.M. Stacey, Fusion Research Center, Georgia Institute of Technology, USA

Dr. John Willis, U.S. Department of Energy, Office of Fusion Energy Sciences, USA

Mr. Paul H. Wright, Indianapolis, Indiana, USA 
The Princeton Plasma Physics Laboratory is operated by Princeton University under contract with the U.S. Department of Energy.

\author{
Information Services \\ Princeton Plasma Physics Laboratory \\ P.O. Box 451 \\ Princeton, NJ 08543
}

Phone: 609-243-2750

Fax: 609-243-2751

e-mail: pppl_info@pppl.gov

Internet Address: http://www.pppl.gov 